\title{
The role of wild carnivores in the maintenance of trichinellosis in the Tatras National Park, Slovakia
}

\author{
Z. HURNÍKOVÁ ${ }^{1}$, B. CHOVANCOVÁ ${ }^{2}$, D. BARTKOVÁ ${ }^{1}$, P. DUBINSKÝ ${ }^{1}$
}

${ }^{1}$ Parasitological Institute of Slovak Academy of Sciences, Hlinkova 3, 04001 Košice, Slovak Republic, E-mail:
hurnikz@saske.sk; ${ }^{2}$ Research Centre of the Tatras National Park, 05960 Tatranská Lomnica, Slovak Republic

\begin{abstract}
Summary
A survey on trichinellosis in wild carnivores and their role in the transmission of parasite in the model territory of the Tatras National Park was conducted in years $2005-2006$. Muscle samples of 102 wild predators representing 10 species belonging to families Canidae, Mustelidae and Ursidae were examined. The highest prevalence of Trichinella britovi was established among red foxes $(19.7 \%)$ and martens $(37.5 \%)$. The parasite was also detected in European polecat and brown bear. No infection was present in wolves, badgers, otters, weasels, and stoats. The results show that in circulation of trichinellosis in nature various carnivore species are included. The high number of infected martens is indicative of their role in maintenance of trichinellosis that should be considered due to synantropic behaviour of these animals.
\end{abstract}

Key words: trichinellosis; carnivores; Tatras National Park; Slovakia

\section{Introduction}

The parasitic nematodes of the genus Trichinella are among the most widespread muscle parasites of predatory and omnivorous mammals as well as scavengers. In the sylvatic cycle, the eating of carrion is considered the principal mechanism of nematode transmission (Campbell, 1988). In most regions of the EU, the specific reservoir of parasite is red fox and is most prevalent among foxes living in either at altitude higher as $400-500 \mathrm{~m}$ above sea level, or in protected and remote areas where the environment is less disturbed. Other carnivores (martens, badgers, bears, lynx, wolves, etc.) may also be infected, but due to low population levels their role in the ecology of sylvatic cycle is only secondary (Pozio, 1998).

In the Slovak Republic trichinellosis in sylvatic cycle is maintained in particular in red fox (Vulpes vulpes) and wild boar (Sus scrofa) as main reservoirs. The substantial increase of red fox population in recent years provides a potential for spread of Trichinella spp. in wildlife. Whereas recent data on trichinellosis in other carnivore species are lacking, we aimed to study the presence of parasite in those animal species, inhabiting the territory of protected areas of the Tatras National Park (TANAP).

\section{Materials and Methods}

In years $2005-2006$, muscle samples were collected from 76 red foxes (Vulpes vulpes), 4 wolves (Canis lupus), 5 stone martens (Martes foina), 3 pine martens (Martes martes) 3 badgers (Meles meles), 3 European polecats (Mustela putorius), 2 otters (Lutra lutra), 2 weasels (Mustela nivalis), 3 stoats (Mustela erminea) and 1 brown bear (Ursus arctos). The animals were shot during the hunting season or were victims of car accidents. The minimum of 10 grams (15 grams when available) of muscle tissue was taken from upper parts of front legs (m. biceps brachii, $m$. triceps brachii) and diaphragm pillars. Each sample was examined individually by artificial $\mathrm{HCl}$ - pepsin digestion method according to Kapel and Gamble (2000). Digested samples were washed twice and examined under a stereomicroscope. Present larvae were counted and stored in $70 \%$ alcohol until molecular species identification. The intensity of infection was calculated as number of larvae per gram of muscle tissue (LPG).

Trichinella larvae, collected from infected individuals, were identified at species level by the multiplex polymerrase chain reaction (multiplex PCR). Extraction of DNA and PCR amplification was done according to Zarlenga et al. (1999) modified to a protocol used at the International Trichinella Reference Centre. The primer pairs were derived from expansion segment V (ESV) and internal transcribed spacer ITS1. The amplification products were separated on an agarose gel and stained with ethidium bromide before visualisation. All PCR reactions included negative 
and positive controls.

\section{Results}

Data from investigation for the presence of Trichinella muscle larvae are presented in Table 1. Trichinella spp. infection was observed in 15 foxes $(19.7 \%), 2$ stone martens $(40.0 \%), 1$ pine marten $(33.3 \%), 1$ polecat $(33.3$ $\%)$, and 1 bear. The intensity of infection in red foxes varied between 0.2 - 6.2 LPG (aver. 2.1 LPG). The martens harboured in 1 gram of muscle tissue 4.6, 4.2 and 11.6 larvae, respectively; the polecat 0.7 larvae; and the bear 57.5 larvae.

The results of molecular analyses revealed exclusive presence of sylvatic species Trichinella britovi. from red foxes resulted T. britovi, 6 T. spiralis and 4 mixed infection with both species. Out 6 examined wolves 3 animals were infected with $T$. britovi, $3 T$. spiralis isolates were obtained from racoon dogs and one marten was found infected with T. spiralis (Cabaj et al., 2004).

Examination of wild carnivores in Slovakia was in the past intensively performed by Mituch, who focused his research especially on the model territory of the Tatras National Park. According to the findings of his investigation conducted in 1956 the prevalence in red foxes was $27.02 \%$, in lynxes $66.6 \%$, in wild cats $15.2 \%$, and in wolves $33.3 \%$ (Mituch, 1957). The same author in 1960 reported 24 positive carnivore hosts out from 134 inspected $(17.9 \%)$ and in 1962 the $19.6 \%$ prevalence in red foxes has been found, with intensity of infection varying between $4-26$ LPG

Table 1. Prevalence of Trichinella britovi in examined carnivores from Tatras National Park, Slovakia in 2005 - 2006

\begin{tabular}{lccc}
\hline \multicolumn{1}{c}{ Host } & No. of animals & Prevalence (\%) \\
\cline { 2 - 4 } Red fox (Vulpes vulpes) & examined & infected & 19.7 \\
Wolf (Canis lupus) & 76 & 15 & 0 \\
Family Canidae & 4 & $\mathbf{1 5}$ & $\mathbf{2 0 . 6}$ \\
Stone marten (Martes martes) & $\mathbf{8 0}$ & 2 & 40.0 \\
Pine marten (Martes foina) & 5 & 1 & 33.3 \\
Badger (Meles meles) & 3 & 0 & 0 \\
European polecat (Mustela putorius) & 3 & 1 & 33.3 \\
Otter (Lutra lutra) & 3 & 0 & - \\
Weasel (Mustela nivalis) & 2 & 0 & - \\
Stoat (Mustela erminea) & 2 & 0 & 0 \\
Family Mustelidae & 3 & $\mathbf{4}$ & $\mathbf{1 9 . 0}$ \\
Brown bear (Ursus arctos) & $\mathbf{2 1}$ & 1 & - \\
Family Ursidae & 1 & $\mathbf{1}$ & - \\
\hline TOTAL & $\mathbf{1}$ & $\mathbf{2 1}$ & $\mathbf{2 0 . 6}$ \\
\hline
\end{tabular}

\section{Discussion}

In total 102 predators representing nine species and belonging to the Canidae, Mustelidae, and Ursidae families were examined. Trichinella britovi larvae were present in muscles of $20.6 \%$ (in 21 out of 102) predators. The most numerous among the examined predators were red foxes. According to our data, the prevalence in this carnivore in the Tatras National Park is higher (19.7\%) than that indicated by long-term study on vulpine trichinellosis performed in entire territory of Slovakia that revealed the prevalence rates from $4.9 \%$ up to $13.3 \%$ (Hurníková et al., 2005). In southern parts of Poland, which is the neighbouring country from the north and the Tatras form a natural borderline, $5.7 \%$ of red foxes have been found to be positive for trichinellosis (Cabaj et al., 2004).

Our finding revealing Trichinella britovi to be only identified species in the TANAP territory is consistent with observations that $T$. britovi is the predominant species in sylvatic populations in Europe (Pozio, 1998). Similar results were obtained in Poland, where out of 74 isolates
(Mituch, 1962). In between 1955 - 1961 examined this author 24 wolves, 13 of them (54.1\%) harboured Trichinella spp. larvae and the intensity of infection was $5-84$ LPG. In 1968, infected brown bear and European weasel were recorded. The presence of nematode was investigated in 31 lynxes and $38.7 \%$ were carriers of Trichinella spp. larvae (Mituch, 1974). A decade later, Hovorka (1987) pointed out decrease of prevalence in many wild carnivore species, with $3.6 \%$ of infected red foxes, and no positive findings in wild cats ( 8 examined), martens ( 8 ex.), stray dogs (28 ex.), wolf (1 ex.), weasels (15 ex.) and lynx (3 ex.). For the first time an infected polecat was identified (out of 6 examined) in 1984 (Hovorka \& Dubinský, 1991). In the Tatras National Park, the last monitoring on trichinellosis was performed in $1988-1989$ by Mituch et al. (1992). 174 carnivores belonging to 9 species were examined, the parasite was absent in most of them except wolf and red fox, with prevalence rates $20.0 \%$ and $5.5 \%$, respectively. The drop in prevalence was considered due to 
further education of hunters, local inhabitants and national park managements. However, results of our present study obtained more than decade later are initiative of fluctuation in the prevalence of trichinellosis in carnivore predators inhabiting the area of national park to higher levels. Trichinella as unspecialised parasite is able to take advantage of several host species and transmission mechanisms related to predation, cannibalism and scavenging. The helminthosis is sustained by the enlarging populations of red fox that is considered both as beast of prey and scavengers. The maintenance and transmission mechanism are conditioned by local food-chains and environments, making specific host accessible. Our investigation results revealed the relatively high number of infected martens and mustelides (37.5\% in martens, $19.0 \%$ in family Mustelidae). These results are in compliance with results obtained by several authors (Pozio et al., 1996; Casulli et al., 2002; Oivanen et al., 2002; Senutaité \& Grikieniené, 2001) emphasizing that in many areas of Europe red fox is not the only wild predator involved in the sylvatic cycle of T. britovi. This confirms the suggestion that mustelids should be also considered when assessing Trichinella epizootology, because of they synantropic behaviour that can represent a link between sylvatic and domestic cycle.

Due to low numbers of samples we regard our study as a pilot survey. More complex investigation is planned in future years to obtain detailed knowledge on role of carnivore species in transmission of trichinellosis in protected area of the Tatras National Park.

\section{Acknowledgements}

The study was supported by the contract No. APVT-51010704. Mr. R. Kubala is thanked for sample collection.

\section{References}

Cabaj, W., Moskwa, B., Pastusiak, K., Bien, J., MalCZEWSKI, A. (2004): Trichinella spiralis and Trichinella britovi in wild and domestic animals in Poland. In Programme and abstracts, Nematode Symposium, 26th November 2004, AFSSA, LEPRAZ, UMR BIPAR, MaisonsAlfort, France, 28

CAMPBEll, W. C. (1988): Trichinosis revisited, another look at modes of transmission. Parasitol. Today, 4: 83 - 86 Casulli, A., La Rosa, G., Amati, M., PoziO, E. (2002): Diet, prevalence of Trichinella infection and impact of hunting in wolves (Canis lupus) of European Russia. Parasitologia, 44: 45
Hovorka, I. (1987): Trichinella species in free living animals in ecological conditions of Carpathian mountain range in Czechoslovakia and singularity evaluation of species belonging to genus Trichinella. Dissertation thesis, Helminthological Institute of SAS, Košice

HovorKA, I., DUBINSKÝ, P. (1991): Trichinella species in free living carnivores in ecological conditions of TANAP. In Proceedings of $1^{\text {st }}$ Symposium on carnivore mammals diseases, 9. - 11.9. 1994, Košice, 70 - 72

HurníkovÁ, Z., ŠnÁBel, V., Pozio, E., Reiterová, K., HrČKovÁ, G., HALÁSOVÁ, D., DUBINSKÝ, P. (2005): First record of Trichinella pseudospiralis in the Slovak Republic found in domestic focus. Vet. Parasitol., 128: 91 - 98

KAPEL, C. M. O., GAMBLE, H. R. (2000): Infectivity, persistence, and antibody response to domestic and sylvatic Trichinella spp. in experimentally infected pigs. Int. J. Parasitol., 30: 215 - 221

MitUCH, J. (1957): Wild carnivores - transfering agents of trichinellosis in the nature. Helminthologia, 3: $104-109$

MituCH, J. (1962): The contribution to knowledge on helminthofauna of red fox (Vulpes vulpes crucigera L.) in Slovakia. Vet. med., 7: 227 - 238 (in Slovak)

MitUCH, J. (1974): To knowledge on helminthofauna of lynx (Lynx lynx L., 1758) in Slovakia. Folia Venatoria, 4: $137-149$ (in Slovak)

Mituch, J., Hovorka, J., Hovorka, I., Világiová, I. (1992): Helminths of carnivores in the model territory of the High Tatra National Park. Folia Venatoria, 22: 191 200 (in Slovak)

Oivanen, L., Kapel, C. M. O., Pozio, E., La Rosa, G., Mikkonen, T., SuKurA, A. (2002): Associations between Trichinella species and host species in Finland. J. Parasitol., 88: $84-88$

PozIO, E. (1998): Trichinellosis in Europen Union: epidemiology, ecology and economic impact. Parasitol. Today, 14: $35-38$

Pozio, E., La Rosa, G., Serrano, F.J., Barrat, J., Rossi, L. (1996): Environmental and human influence on the ecology of Trichinella spiralis and Trichinella britovi in western Europe. Parasitology, 113: 527 - 533

Senutaité, J., Grikieniené, J. (2001): Prevalence of Trichinella in muscles of some domestic and wild mammals in Lithuania and their impact on the organism. Acta Zool. Lituan., 11: 395 - 404

Zarlenga, D. S., Chute, M. B., Martin, A., Kapel, C. M. O. (1999): A multiplex PCR for unequivocal differenttiation of six encapsulated and three non-encapsulated genotypes of Trichinella. Int. J. Parasitol., 29: 141 - 149 